\title{
Asthma Preparation
}

National Cancer Institute

\section{Source}

National Cancer Institute. Asthma Preparation. NCI Thesaurus. Code C29635.

Containing natural or synthetic agents, Asthma Preparations relieve asthma (a recurrent airway obstruction) in various ways by reducing bronchial spasm, dyspnea, allergic reaction, local inflammation, and pain. Anti-asthmatic agents can be mainly bronchodilators (beta-adrenoreceptor agonists, xanthines, muscarinic-receptor antagonists) and anti-inflammatory agents (glucocorticoids, cromolyn). Other agents, such as anti-histamines and antibiotics, may be used in asthma preparations. ( $\mathrm{NCI04)}$ 